\title{
New Three-Phase AC-DC Rectifiers with Reduced Numbers of Switches
}

\author{
Ahmed Darwish", Derrick Holliday and Stephen Finney \\ Electric and Electronic Engineering \\ University of Strathclyde, Glasgow, UK \\ *ahmed.mohamed-darwish-badawy@strath.ac.uk
}

Keywords: ac-dc rectifiers; four-switch three-phase (FSTP) rectifier.

\begin{abstract}
DC-AC rectifiers with reduced numbers of switches, in order to reduce cost, weight, volume and switching losses (especially for low-power applications), have been presented and discussed in the literature. These converters are less exposed to semiconductor switch damage and exhibit lower common-mode currents. However, they have several disadvantages when compared with conventional six-switch three-phase (SSTP) rectifiers, such as dc-link capacitor voltage fluctuation, reduced input ac supply utilisation factor, and unbalanced three-phase input currents. This paper proposes new designs for four-switch three-phase (FSTP) and two-switch single-phase rectifiers (TSSP). This paper explains the normal operation, and proposes beneficial comparisons and performance evaluation, of the proposed rectifiers. In addition, proper control design for the proposed converters is presented with sliding mode control (SMC).
\end{abstract}

\section{Introduction}

Presently, there is an international trend toward the reduction of $\mathrm{CO}_{2}$ production worldwide [1]. Accordingly, the research and development of modern power systems and micro-grids have become more important and significant. Several converter topologies have been proposed and studied in order to enhance their operation, reduce total cost, and improve the efficiency of power systems.

Recently, many researches have considered three-phase Voltage Source Rectifiers (VSRs) with six semiconductor active switches [2]-[4]. and therefore, the literature for these topologies and their control strategies became mature.

However in several low-power applications, converter topologies with lower switch count may be demanded in order to reduce cost and size, and to increase system efficiency. In [5], the first three-phase two-level VSR with only four switches is presented, see Fig.1. In this four-switch three-phase (FSTP) rectifier, two of the input three-phase currents are connected to the two legs of the rectifier while the third phase is connected to the midpoint of the split capacitors across the dc output side. Operation, control design, and performance of FSTP rectifiers have been discussed extensively in the literature [6]-[9].

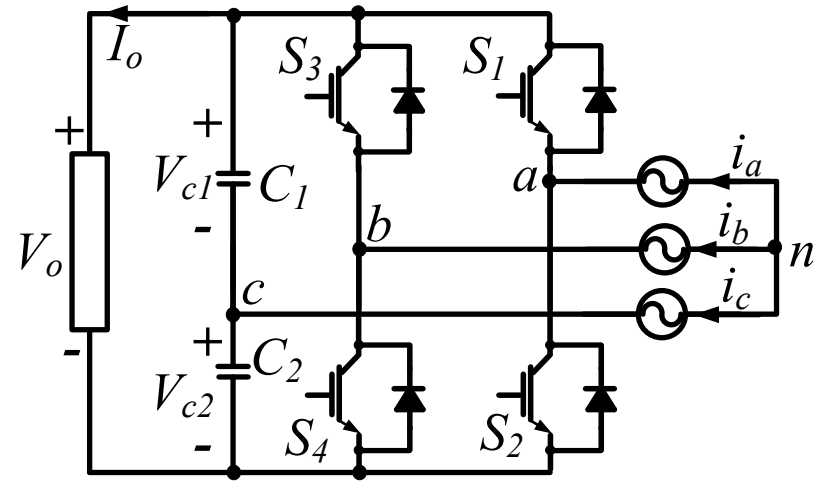

Fig.1. Conventional four-switch three-phase rectifier (FSTP).

The FSTP rectifier has several of the advantages of the conventional VSI, such as reduced total cost and lower power loss: hence, better efficiency can be obtained. In addition, the required numbers of gate drives circuits, measurement boards, and real-time calculations are less in the FSTP rectifier [3].

Moreover, the maximum common-mode current and voltage in FSTP rectifiers are reduced by $33 \%[3,4]$. The FSTP rectifier has lower probability of switch damage as the interaction between the active switches is less. The dc link voltage is doubled in comparison with the six-switch rectifier.

The main disadvantage of the FSTP rectifier is that $\mathrm{dc}$ current components may appear in the input ac current because the third input phase is connected directly to the dc output side. These dc current components are hazardous and a proper control effort should be conducted in order to suppress them. IEEE 1574 standards restrict the dc current components to $<0.5 \%$ of the rated RMS current whilst IEC 61727 standards limit them to $<1 \%$.

In addition, fluctuation of the dc-link capacitor voltage at the fundamental frequency results in fluctuations of the FSTP rectifier input currents. The problem of dc-link voltage oscillation necessitates modified pulse-width modulated (PWM) signals to control and create the desired output voltage during the switching period [10]. Practically, the dclink split capacitors may not have exactly equal capacitance values. Consequently, a control effort should be implemented in order to balance the capacitors voltages [10]. Also, the FSTP rectifier requires higher switching frequency in order to eliminate third-order harmonics from the input ac currents.

From the thirty-three possible two-switch two-diode bidirectional power electronic converters, there are four converters that can provide output voltage with positive and negative polarities. These converters are shown in Fig. 2 as 
two voltage buck and two voltage boost converters. Based on these converters, new three-phase rectifiers with four switches can be generated. Unlike other FSTP rectifiers, the proposed converters do not have direct connection between the ac phases and the dc side voltage. Consequently, the problem of dc current generation in the ac grid does not exist. Moreover, because they do not require direct connection between the ac and dc sides, the proposed converters can operate as ac-dc rectifiers and dc-ac inverters. In ac-dc rectification mode, the proposed rectifiers double the maximum output dc voltage in comparison with the conventional FSTP rectifier.

Unfortunately, the proposed converters are time-variant systems, where the overall transfer function describing the relation between the input and output voltages and currents depends upon the switching periods of the switches. This results in a complex stable design because the converter poles and zeros travel through a long trajectory. Moreover, the timevarying transfer function leads to output voltage and current distortion $[11,12]$. Converter stability and reliability decrease with increasing passive element values. However, reducing the inductor and capacitor values results in larger high-frequency ripple current and voltage components, and hence increases the total harmonic distortion (THD) of the input current and voltage. On the other hand, increasing the passive element values increases the stored energy inside the inverter, producing a third-order harmonic component and its multiples in the input dc current.

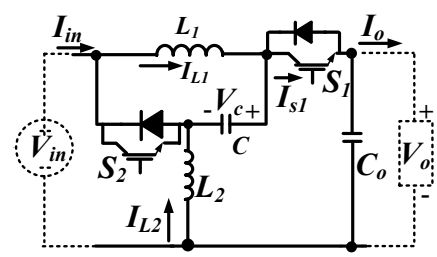

(a) b1G

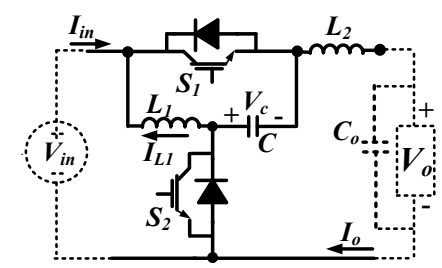

(b) b2G

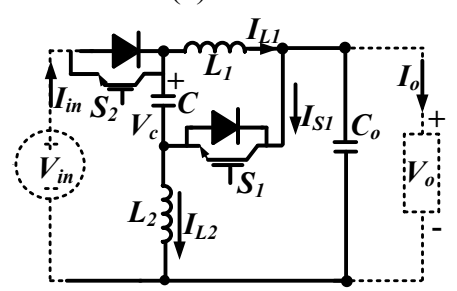

(c) B1G

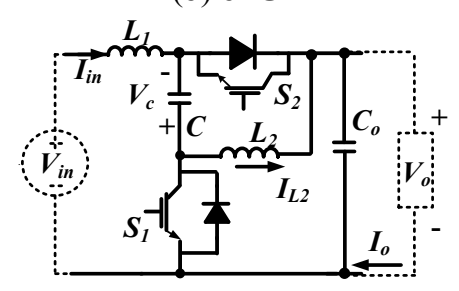

(d) B2G
Fig. 2. DC-DC converters with bidirectional output voltages: (a) and (b) voltage-buck converters, (c) and (d) voltage-boost converters.

This paper presents new rectifier topologies with reduced numbers of switches based on the abovementioned bidirectional dc-dc converters. In addition, proper control design for the proposed converters is presented with sliding mode control techniques (SMC). Practical results substantiate the design flexibility of the proposed topologies when controlled by a TMSF280335 DSP.

\section{DC/DC Converters with Positive and Negative Output Voltage}

The four two-switch two-diode dc-dc converters with positive and negative output voltages are shown in Fig. 2.
Two of these converters are voltage buck converters (b1G and b2G) whilst the other two are voltage boost converters (B1G and $\mathrm{B} 2 \mathrm{G})$. The relationship between the output and input voltages, $V_{o}$ and $V_{\text {in }}$ respectively, is defined by (1), where $M$ is the voltage conversion ratio and $\mathrm{D}$ is the duty ratio of switch $\mathrm{S}_{1}$.

$$
M(D)=V_{o} / V_{\text {in }}
$$

The voltage conversion ratios of the converters can be expressed as (2) and (3).

$$
\begin{array}{ll}
M(D)=\frac{2 D-1}{D} & \text { for } b 1 G \text { and } b 2 G \\
M(D)=\frac{1-D}{1-2 D} & \text { for } B 1 G \text { and } B 2 G
\end{array}
$$

Converter duty ratio $\mathrm{D}$ can be defined as:

$$
D=t_{\text {on }} / t_{s}
$$

where $t_{o n}$ is the duration when switch $S_{l}$ is on, and $t_{s}$ is the total switching period.

Voltage conversion ratios (2) and (3) can be plotted against the duty ratio variation as shown in Fig. 3 .

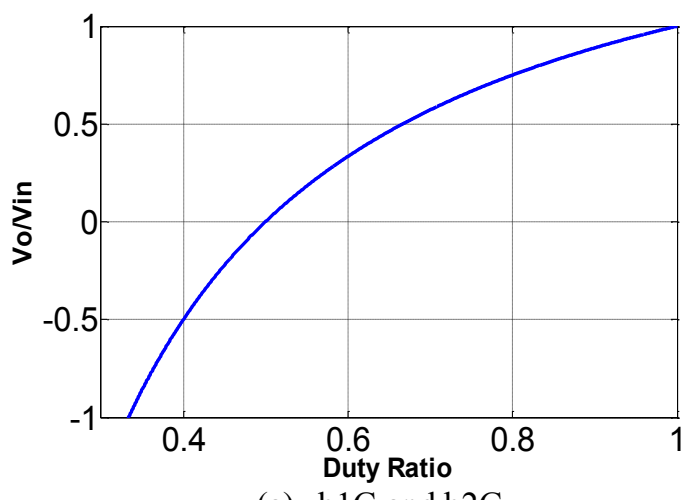

(a) b1G and b2G

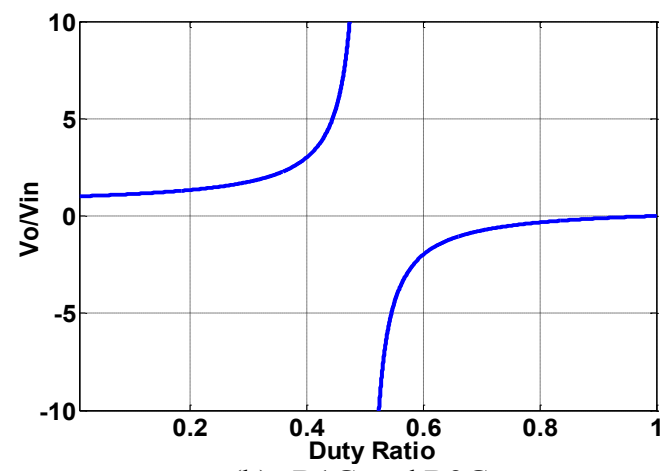

(b) B1G and B2G

Fig. 3. Voltage conversion ratio $\mathrm{M}$ versus duty ratio $\mathrm{D}$.

\section{Four-Switch Three-Phase DC-AC Rectifiers}

The converters shown in Fig. 2(c) and in Fig. 2(d) can both be configured for three-phase operation, as shown in 
Fig. 4(a) and (b) respectively, resulting in four-switch threephase rectifiers. Each boost converter represents one leg of the rectifier, whilst the third phase is connected to ground. The time-variant duty ratios, $\delta_{1}$ and $\delta_{2}$, are calculated from:

$$
\begin{aligned}
\delta_{1}(t) & =\frac{V_{o}-v_{\operatorname{cin} 1}(t)}{2 V_{o}-v_{\operatorname{cin} 1}(t)} \\
\delta_{2}(t) & =\frac{V_{o}-v_{\operatorname{cin} 2}(t)}{2 V_{o}-v_{\operatorname{cin} 2}(t)}
\end{aligned}
$$

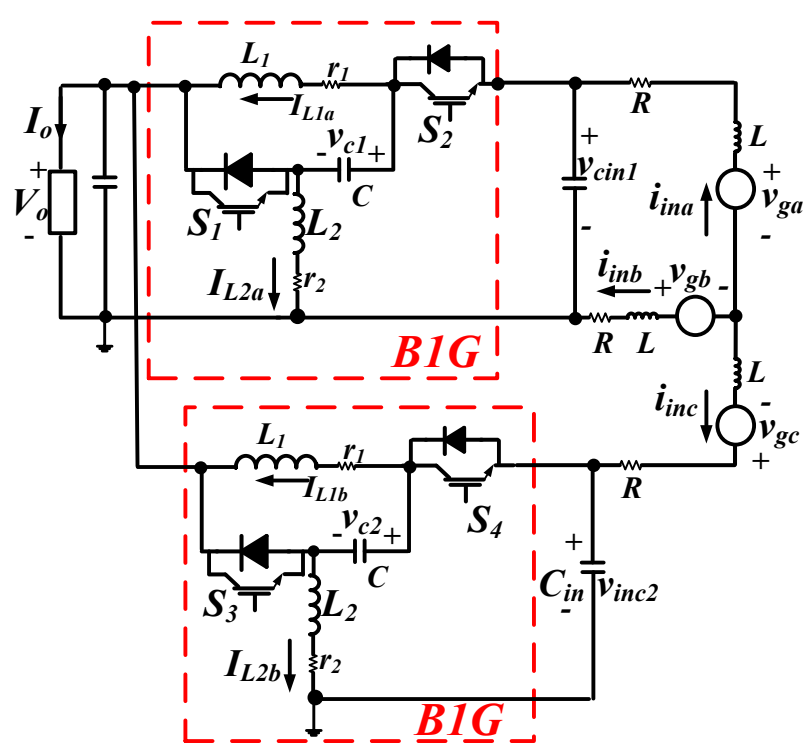

(a)

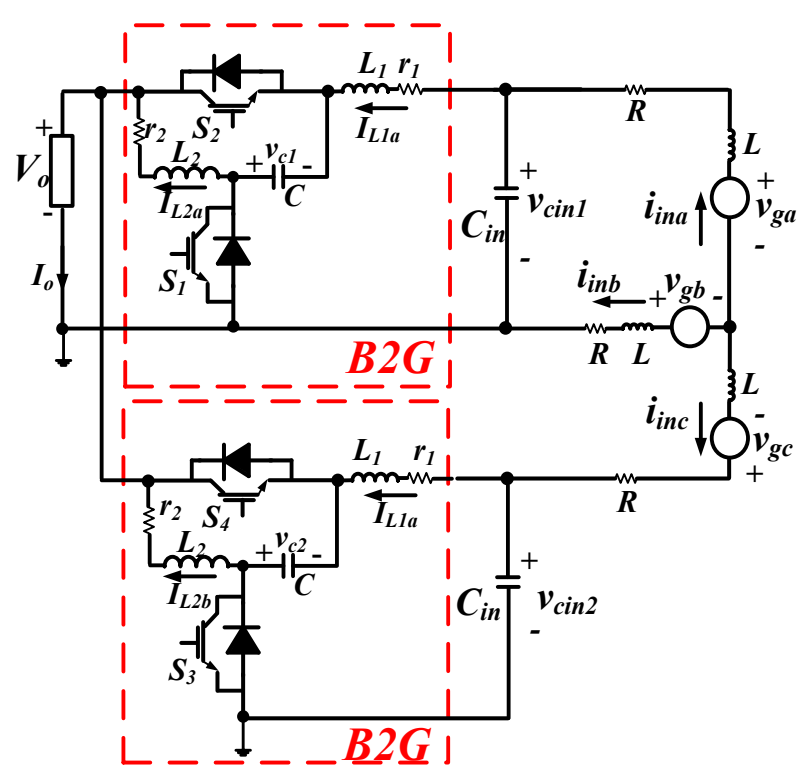

(b)

Fig. 4. Proposed FSTP rectifiers.
The output three-phase voltage can be expressed as:

$$
\begin{aligned}
& v_{g a}(t)=V_{g} \sin \omega t \\
& v_{g b}(t)=V_{g} \sin (\omega t-2 / 3 \pi) \\
& v_{g c}(t)=V_{g} \sin (\omega t+2 / 3 \pi)
\end{aligned}
$$

The generated voltages across capacitors $v_{\text {cin } 1}$ and $v_{\text {cin } 2}$ are:

$$
\begin{aligned}
& v_{\text {cin } 1}(t)=V_{m} \sin (\omega t+\theta) \\
& v_{\text {cin } 2}(t)=V_{m} \sin (\omega t+\theta+1 / 3 \pi)
\end{aligned}
$$

where $\omega=2 \pi f$ is the angular frequency. This causes threephase currents $i_{\text {ina }}, i_{\text {inb }}$ and $i_{\text {inc }}$ to flow from the grid as follows:

$$
\begin{aligned}
& i_{\text {ina }}(t)=I_{\text {in }} \sin (\omega t+\gamma) \\
& i_{\text {inb }}(t)=I_{i n} \sin (\omega t-2 / 3 \pi+\gamma) \\
& i_{\text {inc }}(t)=I_{i n} \sin (\omega t+2 / 3 \pi+\gamma)
\end{aligned}
$$

where

$$
\theta=\tan ^{-1}\left\{\begin{array}{l}
\omega L I_{\text {in }}(\sqrt{3} / 2 \sin (\gamma)-3 / 2 \cos (\gamma))- \\
R I_{\text {in }}(3 / 2 \sin (\gamma)+\sqrt{3} / 2 \cos (\gamma))+\sqrt{3} / 2 V_{g} \\
R I_{\text {in }}(\sqrt{3} / 2 \sin (\gamma)-3 / 2 \cos (\gamma))+ \\
\omega L I_{\text {in }}(3 / 2 \sin (\gamma)+\sqrt{3} / 2 \cos (\gamma))+3 / 2 V_{g}
\end{array}\right\}
$$

and

$$
\begin{gathered}
R I_{\text {in }}(\sqrt{3} / 2 \sin (\gamma)-3 / 2 \cos (\gamma))+ \\
V_{m}=\frac{\omega L I_{\text {in }}(3 / 2 \sin (\gamma)+\sqrt{3} / 2 \cos (\gamma))+3 / 2 V_{g}}{\cos (\theta)}
\end{gathered}
$$

\begin{tabular}{|c|c|}
\hline Parameter & Value \\
\hline$f$ & $50 \mathrm{~Hz}$ \\
\hline$t_{s}$ & $33 \mu \mathrm{s}$ (switching period) \\
\hline$C_{i n}$ & $1 \mu \mathrm{F}$ (Fig. 4(a)) and $5 \mu \mathrm{F}$ (Fig. 4(b)) \\
\hline$C_{o}$ & $2000 \mu \mathrm{F}$ \\
\hline$L_{l}, r_{l}$ & $1 \mathrm{mH}, 0.05 \Omega$ \\
\hline$L_{2}, r_{2}$ & $1 \mathrm{mH}, 0.05 \Omega$ \\
\hline$L$ & $500 \mu \mathrm{H}$ \\
\hline$R$ & $0.5 \Omega$ \\
\hline$V_{g}$ & $300 \mathrm{~V}$ \\
\hline$V_{o}$ & $600 \mathrm{~V}$ \\
\hline
\end{tabular}

Table 1: Parasitic Component Values and Circuit Conditions.

Fig. 5 and Fig. 6 show the open-loop operation of the rectifiers shown in Fig. 4 with the circuit conditions given in Table 1. 


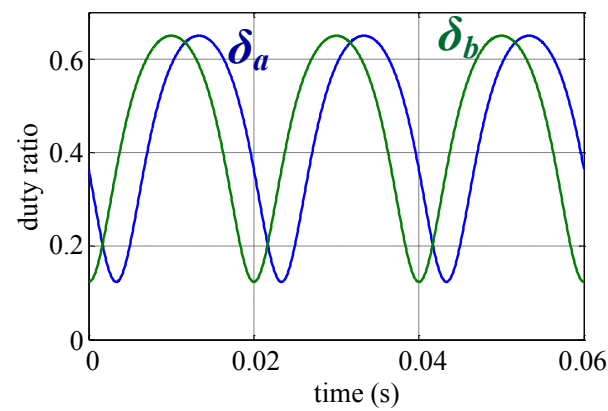

(a) Duty ratios $\delta_{1}$ and $\delta_{2}$

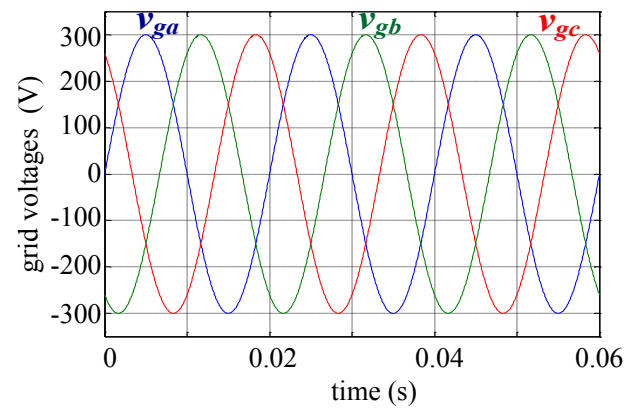

(b) grid three-phase voltage $v_{g a}, v_{g b}$, and $v_{g c}$

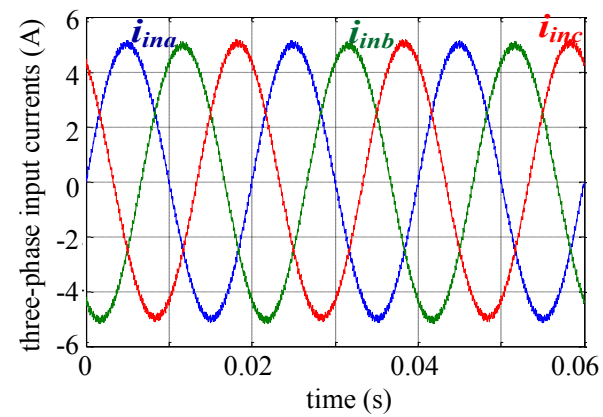

(c) grid three-phase current $i_{\text {ina }}, i_{\text {inb }}$, and $i_{\text {inc }}$

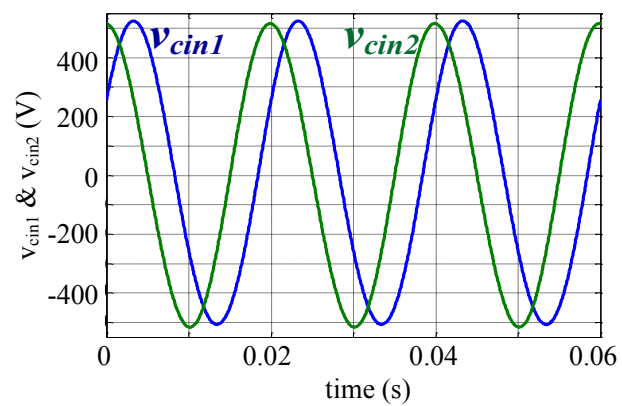

(d) Converters voltages $v_{\text {cin } 1}$ and $v_{\text {cin } 2}$

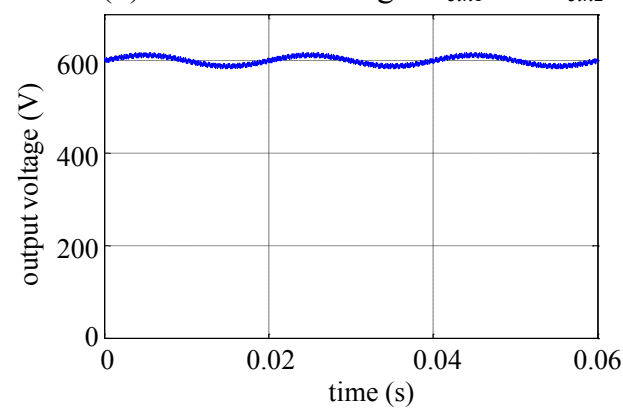

(e) output dc voltage

Fig. 5. Open-loop B1G rectifier operation.

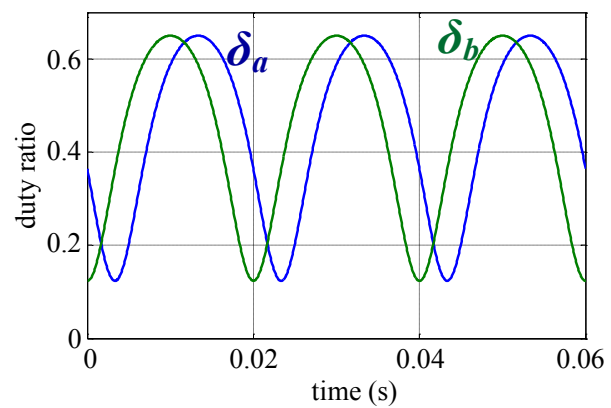

(a) Duty ratios $\delta_{1}$ and $\delta_{2}$

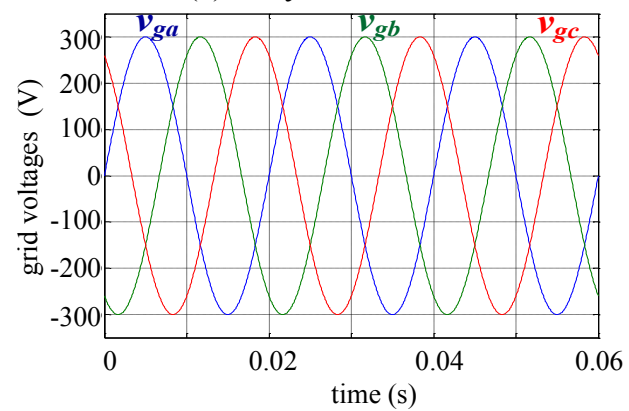

(b) grid three-phase voltage $v_{g a}, v_{g b}$, and $v_{g c}$

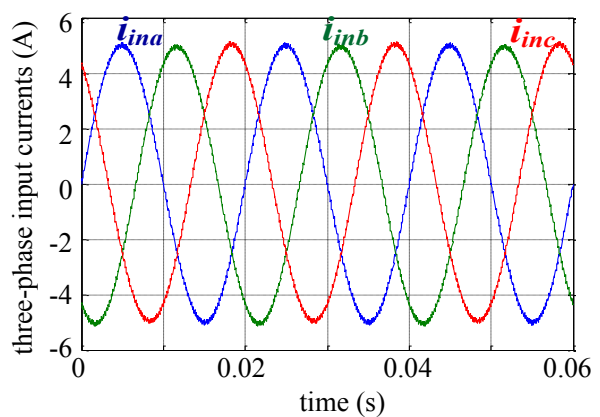

(c) grid three-phase current $i_{\text {ina }}, i_{\text {inb }}$, and $i_{\text {inc }}$

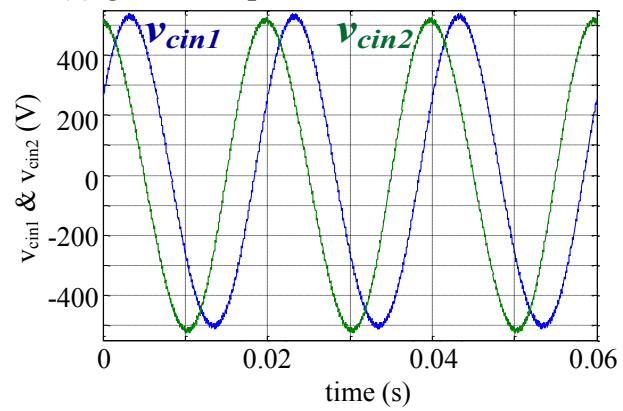

(d) Converters voltages $v_{\text {cin } 1}$ and $v_{\text {cin } 2}$

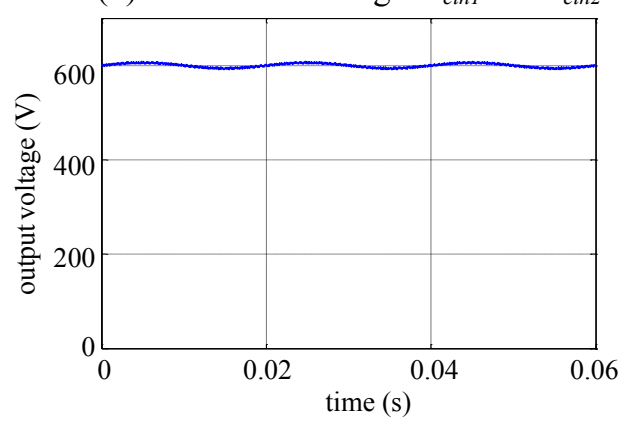

(e) output dc voltage

Fig. 6. Open-loop B2G rectifier operation. 


\section{State-Space Modelling and Control Strategy}

The $\mathrm{B} 1 \mathrm{G}$ and $\mathrm{B} 2 \mathrm{G}$ converter circuit configurations are shown in Fig. 7 and Fig. 8, which include the inductor parasitic resistances $r_{1}$ and $r_{2}$, and the output inductance and resistance $L$ and $R$. The duration $t_{o n}$ defines the period that either $S_{I}$ or its anti-parallel diode is conducting. The average models of the converters are expressed in (12) and (13). The converter pole-zero maps in Fig. 9 and Fig. 10 show that the dynamics of the converters change with the small-signal duty ratio $\delta$.

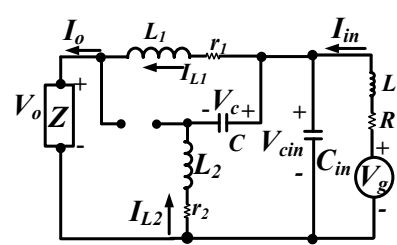

(a) $0 \leq t<t_{\text {on }}$

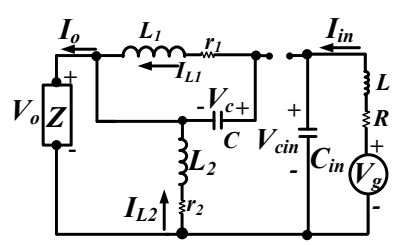

(b) $t_{\text {on }} \leq t<t_{s}$
Fig. 7. B1G converter configurations.

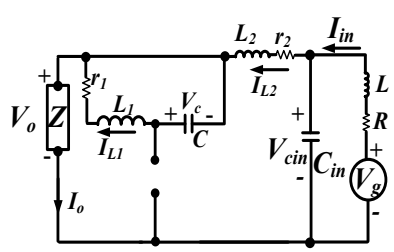

(a) $0 \leq t<t_{\text {on }}$

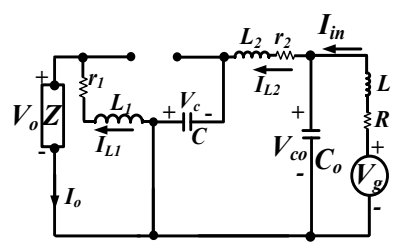

(b) $t_{\text {on }} \leq t<t_{s}$
Fig. 8. B2G converter configurations.

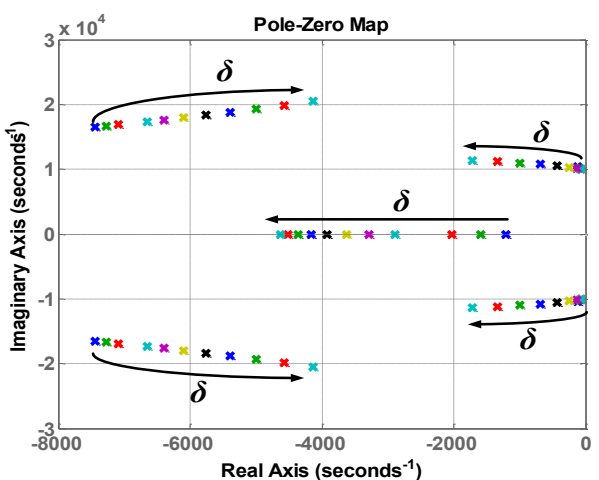

Fig. 9. B1G converter pole-zero map.

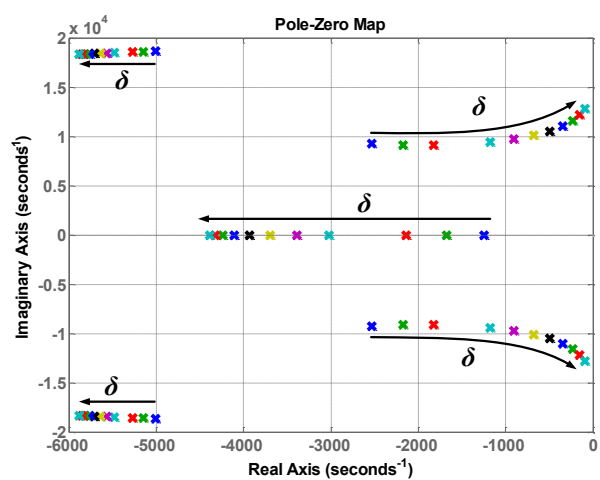

Fig.10. B2G converter pole-zero map.

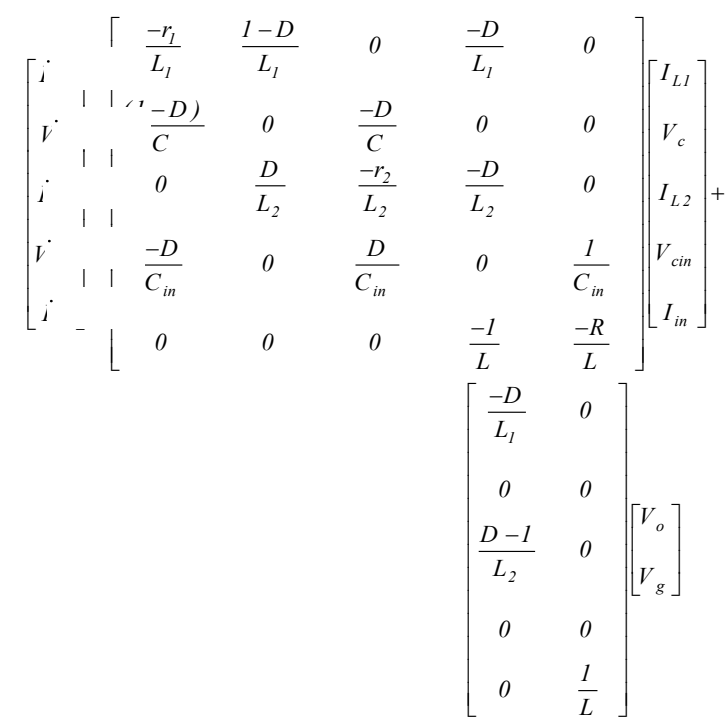

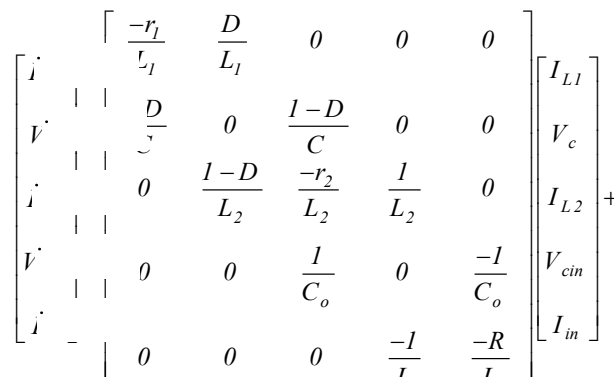

$$
\begin{aligned}
& {\left[\begin{array}{cc}
\frac{D-1}{L_{1}} & 0 \\
0 & 0 \\
\frac{-D}{L_{2}} & 0 \\
0 & 0 \\
0 & \frac{-1}{L}
\end{array}\right]\left[\begin{array}{l}
V_{o} \\
V_{g}
\end{array}\right]}
\end{aligned}
$$

Because the proposed inverters are high-order systems, Variable Structure Control [13] (VSR) is an attractive solution. Sliding Mode Control (SMC) [13], which belongs to a family of VSR techniques, is applied to the proposed rectifier. To shows the validity of the concept, the SMC for the proposed rectifier (B1G) is shown in Fig. 11, where $r_{l}$ and $r_{2}$ are the parasitic resistances of $L_{1}$ and $L_{2}$ respectively. $K_{1}, K_{2}, K_{3}$ are controller gains, which are selected as per [14]. Fig. 12 shows the experimental results for the B1G rectifier when load $Z=55 \Omega$. The efficiency of the rectifier is $97 \%$.

\section{Conclusion}

This paper presents new ac-dc rectifier topologies, based on bidirectional dc-dc converters, with reduced numbers of switches. The proposed rectifiers have better voltage utilisation than the conventional FSTP rectifier and do not draw dc currents from the input dc side. Single-phase rectifiers with fewer switches and better voltage utilisation factor can be obtained from the same power converters. State 
space representation was used to demonstrate the dynamic response and robustness of the proposed rectifiers. However, the proposed inverters are high-order systems where the transfer function poles move with duty ratio variation. Consequently, classical control strategies are not easily implemented with these converters. The basic control structure, control design using sliding mode controllers, and MATLAB/SIMULINK results are presented, along with practical results to substantiate the design flexibility of the proposed topologies when controlled using a TMSF280335 DSP. Full comparisons between the proposed types of rectifiers, as well as conventional rectifiers in the literature, in terms of power loss, voltage regulation, THD, etc. will be considered in future publications.

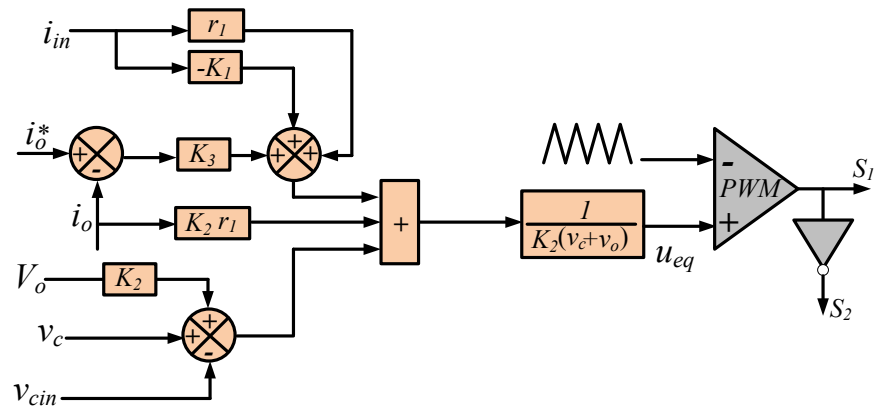

Fig. 11. FSTP rectifier sliding mode control.

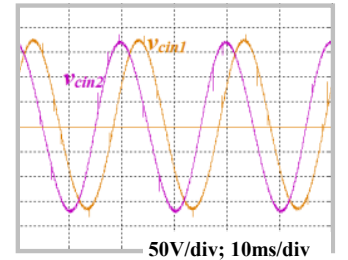

(a) converter input voltages

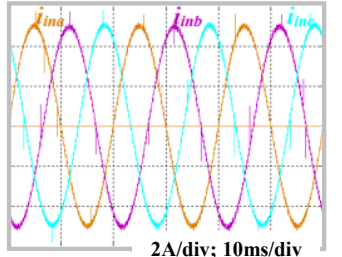

(b) input current $i_{\text {ina }}, i_{\text {inb }}, i_{\text {inc }}$

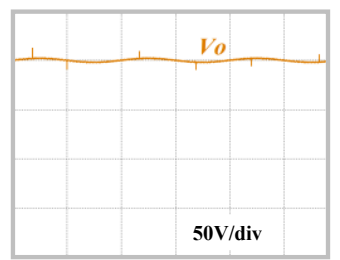

(b) output de voltage

Fig. 12. Experimental results for B1G FSTP $\left(V_{g}=100 \mathrm{~V}, V_{o}=200 \mathrm{~V}\right.$ and $\left.Z=55 \Omega\right)$.

\section{Acknowledgement}

The authors gratefully acknowledge the support of the EPSRC Underpinning Power Electronics 2012: Converters Theme project, Grant No. EP/K035096/1.

\section{References}

[1] Y. Xue, J. Deng, and S. Ma, "Power flow control of a distributed generation unit in micro-grid," in Proc. IEEE Int. Power Electron. Motion Control Conf., 2009, pp. 2122-2125
[2] B. Singh, B.N. Singh, A. Chandra, K. Al-Haddad, A. Pandey, and D.P. Kothari, "A review of three-phase improved power quality AC-DC converters," IEEE Trans. Ind. Electron., vol. 51, no. 3, pp. 641-660, Jun. 2004.

[3] J.R. Rodriguez, J.W. Dixon, J.R. Espinoza, J. Pontt, and P. Lezana, "PWM regenerative rectifiers: State of the art," IEEE Trans. Ind. Electron., vol. 52, no. 1, pp. 5-22, Feb. 2005.

[4] D.C. Lee, G.M. Lee, and K.D. Lee, "DC-Bus voltage control of threephase AC/DC PWM converters using feedback linearization," IEEE Trans. Ind. Appl., vol. 36, no. 3, pp. 826-833, May 2000

[5] G.T. Kim and T.A. Lipo, "VSI-PWM rectifier/inverter system with a reduced switch count," IEEE Trans. Ind. Appl., vol. 32, no. 6, pp. 1131-1137, Nov. 1996.

[6] J. Klima, J. Skramlik, and V. Valouch, "An analytical modelling of threephase four-switch PWM rectifier under unbalanced supply conditions," IEEE Trans. Circuits Syst. II: Express Briefs, vol. 54, no. 12, pp. 1155- 1159, Dec. 2007.

[7] M. Monfared, H. Rastegar, and H.M. Kojabadi, "Overview of modulation techniques for the four-switch converter topology," Conf. Rec. IEEE Power Energy Conf., Dec. 2008, pp. 803-807.

[8] S. Ounie and M.R. Zolghadri, "Space vector modulation for four-switch rectifier with compensating the effect of capacitors voltage ripple," Conf. Rec. IEEE Ellsworth Prototype Entry Control Syst. (EPECS), pp. 861-866, Dec. 2009.

[9] T.S. Lee, and J.H. Liu "Modeling and Control of a Three-Phase Four-Switch PWM Voltage-Source Rectifier in d-q Synchronous Frame," IEEE Trans. On Power Electron., vol. 26, no. 9, pp. 2476-2489, Sept. 2011.

[10] M. Monfared, H. Rastegar, and H.M. Kojabadi, "Overview of modulation techniques for the four-switch converter topology," in Power and Energy Conference, 2008. PECon 2008. IEEE 2nd International, vol., no., pp.803-807, 1-3 Dec. 2008

[11] A. Darwish, D. Holliday, S. Ahmed, A.M. Massoud, and B.W. Williams, "A Single-Stage Three-Phase Inverter Based on Cuk Converters for PV Applications," IEEE Journal of Emerging and Selected Topics in Power Electronics, vol. 2, pp. 797-807, 2014.

[12] P.R. Prasanna and A.K. Rathore, "Analysis, Design, and Experimental Results of a Novel Soft-Switching Snubberless Current-Fed Half-Bridge Front-End Converter-Based PV Inverter," IEEE Transactions on Power Electronics, vol. 28, pp. 3219-3230, 2013.

[13] V. Utkin, J. Guldner, and J.X. Shi, Sliding Mode Control in Electromechanical Systems. London, U.K.: Taylor and Francis, 1999

[14] A.D. Badawy, " Current source dc-dc and dc-ac converters with continuous energy flow," Degree of Doctor of Philosophy, Departement of Electronics and Electrical Engineering, University of Strathclyde, Glasgow, 2015. 